\title{
O CORPO EM TRÂNSITO NA POESIA DE JORGE DE SENA
}

Fernando Miranda é doutorando em Literatura Comparada pela Universidade Federal Fluminense (UFF/CAPES), com tese sobre corpo e memória nas obras poéticas de Hilde Domin, Jorge de Sena e João Cabral de Melo Neto, sob orientação da professora Dra. Susana Kampff Lages.

e-mail: fernandogalo@hotmail.com

\section{Resumo}

O objetivo deste trabalho é refletir sobre alguns aspectos do corpo na obra de Jorge de Sena e fazer uma relação com os comentários de Giorgio Agamben respeito ao papel das identidades biológica e política na sociedade atual.

\section{Resumen}

El objetivo de este artículo es reflexionar acerca de algunos aspectos del corpo en la obra de Jorge de Sena y relacionarlos con la observación de Giorgio Agamben sobre el rol de las identidades biológica y política en la sociedad actual.

Em ensaio publicado na versão brasileira da revista Le Monde Diplomatique, o filósofo italiano Giorgio Agamben chama a atenção para o fato de que a obsessão por segurança, ocorrida em diversos Estados do mundo, estaria provocando um processo de despolitização, pois "pela primeira vez na história da humanidade, a identidade não é mais função da 'pessoa' social e de seu reconhecimento, do 'nome' e da 'nomeação', mas de dados biológicos que não podem manter nenhuma relação com o sujeito" (2014, p. 26). Agamben ainda salienta o risco de se estabelecer, como parâmetro político, aquilo que está para além de suas vontades, i.e., seus dados biológicos, gerando um "primado da identidade física sobre a identidade política" (p. 26). Cabe realçar que já não se trata pura e simplesmente dos aspectos exteriores do corpo, da sua aparência, mas sim de elementos biométricos, apenas capazes de ser medidos por aparelhos, ou seja, impossíveis de ser reconhecidos por outro ser humano. Esta prática de controle é, segundo o filósofo, ainda mais severa, em alguns aspectos, que "a dos Estados fascistas do século XX" (p. 25). A partir desta colocação, procuro refletir acerca do corpo e de seu espaço e configuração políticos em alguns poemas do português Jorge de Sena, quem se exilou justamente de um destes Estados totalitários do século XX: o Portugal, do governo de António de Oliveira Salazar. Logo, farei uma articulação entre as leituras dos poemas e as ideias de Agamben, citadas acima, num exercício que visa a estabelecer uma fusão de horizontes entre meados do século XX e a atualidade, no que diz respeito ao tema aqui proposto.

Para além dos seus aspectos receptivos - visão, audição, olfato, paladar e tato -, pelos quais o ser humano sente/percebe o mundo que o cerca, não apenas de forma imediata, mas, desde muitos séculos, também de modo mediado, principalmente a partir do século XX, o corpo, além de ocupar, enquanto matéria, um espaço, possui aberturas através das quais ele comunica, se expressa, procura estabelecer uma relação ativa com o mundo e com os demais indivíduos. Nesta relação, ele construirá a sua identidade, pelo gestual, pelo olhar e pela voz. Cito o poema "O ecumenismo lusitano ou a dupla nacionalidade", de Jorge de Sena:

Pela porta lateral da catedral em Colónia (construída - è vero - para os ossos dos Reis Magos) eu saía para o branco sol da manhã de inverno, quando um rumor de português subia em negros hábitos a escada. Freiras a quem falei sim brasileiras peregrinas de pouso em pouso a Roma. Quando eu disse que eu era brasileiro a madre cujo véu 
rodeava um rosto emaciado e luso

disse: - Ah, naturalizado, não é brasileiro - .

$\mathrm{O}$ outro caso foi em Hamburgo na

Hauptbahnhof. O quiosque dos jornais

de todas as línguas. Chega uma mulher

morena - um traço dentro de opulentas peles - e pergunta

por jornais lusitanos em alemão razoável.

Era evidente que só um português dos tais desejaria

em Hamburgo informar-se assim do estado do universo.

É portuguesa? Sou. Palavra puxa palavra,

eu também era. Mas ela exclamou:

- Brasileiro naturalizado? Ah, não é português -.

E voltou-me as costas com o periódico na mão,

equilibrando as pernas ainda de varina

dificilmente nos tacões finíssimos. (2004, pp. 99-100)

Publicado em Exorcismos, de 1972, e depois presente na recolha Poesia III, que inclui ainda Peregrinatio ad loca infecta, Camões dirige-se aos seus contemporâneos, Conheço o sal...e outros poemas e Sobre esta praia, o poema, datado de 20 de janeiro de 1970, pertence à fase do segundo exílio seniano, nos Estados Unidos, após o primeiro período no Brasil. Apesar de nenhuma cidade acompanhar a data, como ocorre em outros poemas, fica explícito, desde o primeiro verso, que o poeta se encontra na Alemanha. Em rigor, é possível considerar uma terceira fase do exílio seniano, demarcado por sua primeira volta à Europa, nove anos depois de ter cruzado o Atlântico rumo ao Brasil. Deste modo, o próprio Sena proporá uma espécie de diapasão para a leitura de seus "poemas de exílio". No prefácio a Exorcismos, escreve: "Viver exilado não é o mesmo que viajar, a não ser para quem considere, do canto da sua aldeia, que todo o resto do mundo está em viagem só porque não vive ali mesmo" (1978, p. 115).

Esta diferença basilar entre o estar-em-trânsito do exilado e do viajante ainda poderia desdobrar-se em outras questões, como a do exilado voluntário e a do exilado político. O primeiro deixa seu lugar de origem sem que tenha sido forçado a isso; o segundo, perseguido por um regime totalitário, deve fugir, se pretende preservar a sua vida. Entretanto, não é um dado menor que Sena tenha incluído, em Exorcismos, poemas inspirados "por lugares em viagem" (p. 115), exceto "os que foram escritos em Portugal (Agosto 1971)" (p. 115).

De volta ao poema, encontra-se, logo no quarto verso, "um rumor de português que subia". Reparo que o reconhecimento do idioma é dado de forma sutil, através deste "rumor", ou seja, de algo que ainda não é nítido. Este traço de familiaridade, proporcionado pelo idioma materno, desperta o eu-lírico, que "saía para o branco sol da manhã de inverno", num movimento de explícita oposição entre o escuro recolhimento de uma catedral e a abertura para a amplitude do exterior. O som da língua materna é percebido, portanto, no exato instante em que o olhar ainda se adapta à passagem de ambientes. O segundo momento em relação ao reconhecimento da língua é o de identificação da origem, quando o eu-lírico percebe tratar-se de português brasileiro. No diálogo, a pergunta permanece em elipse, e a resposta das religiosas - "sim brasileiras peregrinas/ de pouso em pouso a Roma" - é inserida sem aspas ou travessão, fazendo parte da voz do poeta ao leitor. A voz de uma das madres só aparecerá no décimo verso, na afirmação "Ah, naturalizado, não é brasileiro". Mais do que um espanto, o "ah" parece indicar um desapontamento, ao saber que o interlocutor que recém a abordara não era um brasileiro legítimo, mas um naturalizado, um conterrâneo de segunda mão. Independentemente de o poeta declarar-se naturalizado ou não, a sua própria voz o 
desmascararia, por causa do sotaque português, aspecto material que dificilmente pode ser disfarçado e que se torna, assim, constituinte desta identidade política, muito mais que o timbre de voz, algo que permanece no nível individual.

Os próximos 13 versos narrarão uma história semelhante, ocorrida em Hamburgo. Aqui, no entanto, o sotaque será o disfarce. A mulher, portuguesa, toma o eu-lírico como um compatriota, até espantar-se e dizer "Brasileiro naturalizado? Ah, não é português". Antes, porém, ela só tinha sido reconhecida como portuguesa por ter perguntado "por jornais lusitanos", pois "só um português dos tais desejaria" saber, deste modo, "do estado do universo". Traço típico da obra seniana, a ironia costuma ser reservada a Portugal. O fato de ela ter falado em "alemão razoável" pode ter simulado esta certeza que se dava através do objeto pedido. Neste episódio, foi necessário sair da materialidade do idioma para entrar nas suas produções de sentido (Gumbrecht, 2010). Tanto pelo lado do poeta, que desconfia da nacionalidade da mulher por causa do interesse no jornal, quanto por parte dela, que só pode saber da dupla cidadania do poeta se ele a anunciou. Caso contrário, o modo de falar português jamais permitiria saber este viés brasileiro, que a fez, inclusive, dar as costas a ele, ignorando-o, sem sequer despedir-se.

Nos dois casos, o poeta viu-se como um ex-patriado, configurando o entre-deux (Sibony, 1991) não como uma dupla pertença, mas como dupla perda: nem brasileiro, nem português. Nas duas cenas, bastante breves, nenhuma aparência corporal identificou nem a si nem a suas interlocutoras. De fato, no segundo caso apenas uma questão política - a naturalização - pôde estabelecer um canal para que a portuguesa "dentro de opulentas peles" pudesse dar as costas ao poeta e ir embora. O uso do adjetivo "morena", além das "opulentas peles", provocaria a pensar numa descrição típica de uma brasileira na Europa. Operar com este estereótipo que culminará numa portuguesa - uma compatriota, portanto - que o ignora, leva à percepção da fragilidade da aparência física no que diz respeito à nacionalidade. Ironicamente, ao ser preterido, o poeta se refere a ela de um modo jocoso, ao afirmar que ela se vai "equilibrando as pernas ainda de varina/ dificilmente nos tacões finíssimos". A falta de elegância no andar se associa à falta de elegância que ela demonstrara no lidar com ele.

O poema apresenta estes dois casos, não divididos por estrofes. Apenas um ponto final, no verso dez, marca o fim da primeira história. Após a segunda cena, contada mais pausadamente - divisão em cinco, dois, três e três versos, marcados pelo ponto final - não há um fechamento, uma voz que tenta abstrair dos dois acontecimentos alguma lição moral ou algum ensinamento político-filosófico. Isto se deixar ler na volta ao título: "O ecumenismo lusitano ou a dupla nacionalidade". Há, claramente, uma crítica, expressa uma vez mais pela ironia, a este "ecumenismo lusitano" que, invés de agregar os povos, separa-os. Não há, portanto, nada de ecumênico para este indivíduo de dupla nacionalidade. Sem conseguir unir as duas, ele se separou - ou foi separado - de ambas. Sem alterar sua identidade biológica, Jorge de Sena passou de português a brasileiro naturalizado, morando nos Estados Unidos, e tendo encontrado, casualmente, três colusitanas, na Alemanha. Este corpo em trânsito não carrega marcas identitárias na sua aparência, pois aspectos físicos como cor de pele, cor dos olhos, formato da cabeça, etc, devem ser relativizados, num mundo em que as fronteiras, cada vez mais delimitadas geopoliticamente, não têm correspondido a outros tipos de fronteiras, como a das relações humanas. Apesar de o poema ter sido escrito há mais de quarenta anos, quando a configuração mundial seguia outra ordem, o que se depreende daquelas duas cenas ainda mantém uma pulsão crítica a sistemas e propostas que visem a impedir uma aproximação entre indivíduos. Não são apenas as angústias de 
Sena, sujeito duplamente negado, mas as de todos aqueles que sofrem a rejeição e o preconceito. Como ressalta Adorno,

o teor [Gehalt] de um poema não é mera expressão de emoções e experiências individuais. Pelo contrário, estas só se tornam artísticas quando, justamente em virtude da especificação que adquirem ao ganhar forma estética, conquistam sua participação no universal. Não que aquilo que o poema lírico exprime tenha de ser imediatamente aquilo que todos vivenciam. Sua universalidade não é uma volonté de tous, não é a da mera comunicação daquilo que os outros simplesmente não são capazes de comunicar.(2003, p. 66)

Para pensar sobre o corpo como um espaço livre que se relaciona com outros espaços, cito o poema "Raízes", de Conheço o sal..., e também presente em Poesia III. Por tratar-se de um poema longo - 36 versos - reproduzirei, aqui, a partir do décimo primeiro verso, dividindo-o em três partes.

Raízes? Como - por metáfora - se ganham ou se perdem? Sendo filho? Sendo pai? As duas coisas?

Vivendo aqui na pátria ou mais ou menos do que quantos anos?

Perderam-nas Camões e Mendes Pinto no Oriente?

Ganhou-as Eça nos seus exílios de consul?

Manteve-as fumos de ópio aquele Camilo

apenas Pessanha por Macau? Ganhou-as

Pessoa tão inglês de sul das Áfricas,

no seu tão esperto exílio de Lisboa?

E o Vieira padre e brasileiro na Bahia,

largara-as lá por Roma à Cristina da Suécia?

Miguéis em Nova-York? O Pimentel das Memórias

perdeu-as em São Paulo? Este país - que sempre isto pergunta -

aonde tem raízes? Certamente que

à volta de Paris - com um milhão de raízes

a fazer filhos (e não porque em Paris

se escreva ou se traduza o lido em Portugal). (2006, p. 228)

Num encadeamento de interrogações, Sena retoma nomes que viriam a compor parte do cânone da Literatura Portuguesa. Entre todos os citados, um aspecto comum: a distância - física - em relação a Portugal. Poder-se-ia argumentar em favor de uma cultura que desde a época dos Descobrimentos - e mesmo antes disso - se lança para além dos limites de seu território. O poeta não deixa, no entanto, de realizar mais uma de suas muitas críticas, ao ironizar esta cultura - literária - que se desenvolve "à volta de Paris". A importação de modas e tendências francesas, o que decerto não é exclusividade de Portugal, não se adequa, porém, aos nomes que aparecem no poema. Também Jorge de Sena se insere nesta tradição, e não seria ocioso questionar-se se, neste encadeamento, ele não seria o próximo incluído. Deste modo, o poeta se associa politicamente aos demais autores não por ideologias, crenças ou simplesmente por ter nascido em Portugal; o que os une, o que os faz politicamente próximos, é estar neste outro espaço, nem físico nem ideal, mas virtual: o espaço literário. É esta, por fim, a única consciência coletiva possível, porque nascer em Portugal poderia ser acaso ou indiferença, se todos estes autores não tivessem mantido, em menor ou maior grau, uma relação - enraizada? - com a terra natal. Não se pode falar em identidade biológica - ou física, se se prefere -, e mesmo uma identidade étnica permanece em dúvida, neste caso. A adesão político-literária é uma escolha. Obviamente, poder-se-ia isolar cada autor e 
intensificar a problematização aqui tratada. No entanto, isto não cabe no presente trabalho.

Esta inquietação seniana em relação à pátria e ao lugar não é um caso raro em sua vasta obra. Como ressalta Maria Alzira Seixo (2001, p. 128-131), algumas das linhas temáticas da poesia de Jorge de Sena são

a problemática da esperança e do lugar, encarado o lugar como possibilidade fundamental de habitação, de ocupação do espaço físico por forças e intensidades humanas, e concebida a esperança como possibilidade de fundação desse lugar de sonhado, marca física de um futuro que só concretizado em espaço pode apreender, um espaço que é reduto e medida do homem; a problemática da pátria, que no fundo quase iguala a de todo o ser e objecto amado, e que é desejada e simultaneamente repelida pelo desgosto de não ser o que dela (ou deles) se espera (...).

O poeta, longe da inocência, sabe que este fenômeno não é algo novo nem exclusivo da cultura portuguesa:

E isto é velho como o mundo: ao grego Heródoto uns gregos que ele achou pelos Egitos,

aos quais - tu quoque... - perguntou pelas raízes, apontaram-lhe num gesto (lusitano)

qual a raiz que tinham radicada neles. (Ibidem, p. 228)

Neste ponto, pode surgir uma tendência a querer buscar um percurso das diásporas, partindo desde

a queda de Samaria em 721 ou a deportação para Babilônia em 586 antes da nossa era, até às perseguições nazi-fascistas do século XX, passando pela expulsão, nos séculos XV e XVI, daqueles judeus sefarditasque se haviam instalado na Península Ibérica desde que o imperador Tito destruíra Jerusalém, no ano 70. (Lourenço, 2009, p. 332)

No entanto, é preciso observar, no interior de cada dispersão (diáspora), suas motivações e seus desdobramentos, além das condições e referências (políticas, religiosas, econômicas, etc) existentes não apenas no período em que elas ocorreram, mas nos limites geográficos em que elas se deram. Apesar de Jorge de Sena se referir a ele mesmo como exilado, um termo que melhor caberia, e que o próprio poeta usou em alguns de seus textos, como em $O$ reino da estupidez, é estrangeirado. Onésimo Teotónio Almeida afirma que

estrangeirados são (...) os modernos, aqueles cuja maneira de ser, por natureza ou por educação e contágio, lhes fez sentir demasiado apertada a camisa de varas em que a cultura portuguesa se foi fechando, constrangendo o crescimento, a abertura de horizontes, o diálogo com a Europa do centro e do norte (2009, p. 327).

A partir desta definição, noto a ausência de determinação política, como no caso do exilado, pois o que está em debate é o eventual limite que uma dada cultura impõe ao indivíduo, que, durante sua formação, se verá restringido, ou, para acompanhar uma metáfora do corpo, mutilado. Aqui, tem-se a raiz cortada ou mesmo a necessidade ética de supressão desta raiz, a não ser que o sujeito queira sempre aceitar estar atrelado a este corpo maior, o do Estado. 
O poema se encerra com a recordação de que há outros tipos de raízes, todas elas relacionadas a esta arte humana de cultivar, seja obras de arte, objetos práticos, ideias, conceitos.

Raízes outras há: os mortos que nos dormem na terra em que nascemos, na terra onde morreram, e nos vivem na vida que não tendes nesta Europa finis pilritos fêmeas de outros mundos machos. (Ibidem, p. 229)

Prevalecer nesta cultura humana é resistir a diversos processos de coisificação e automatização do ser humano em nome de um progresso cujo télos não é nem explicitado discursivamente nem se insinua revelador. Retorna-se à voz, pois é com ela que se faz o poema, mesmo quando percebida apenas pelo ouvido interior. Se a literatura é "um movimento para o exterior - a partida de um corpo em direção a outro" (Lima, 2013, p. 3), então o corpo se põe para esta atividade tanto sensitiva quanto intelectual, num uno que não pretende dissipar-se nem no erótico nem no cogito, mas manter a tensão entre eles, no interior da própria poética, pois

a idiossincrasia do espírito lírico contra a prepotência das coisas é uma forma de reação à coisificação do mundo, à dominação das mercadorias sobre os homens, que se propagou desde o início da Era Moderna e que, desde a Revolução Industrial, desdobrou-se em força dominante da vida. (Adorno, 2003, p. 69)

É também importante chamar a atenção para os riscos das "raízes" em épocas de governos totalitaristas - ou mesmo na fase anterior da subida destes governos ao poder -, pois a ideia de pertença pode levar a uma obediência cega e à cesura das liberdades individuais, não apenas à das diretamente impostas pelo governo, mas a uma autonegação - ou autoanulação - em nome de um projeto maior que não requer o bemestar para todos - ainda que seja esta a sua base ideológica -, mas o controle de ações que não dizem respeito a um organismo maior - o Estado, no caso - que se alimenta do que essas raízes são capazes de absorver. Com os últimos quatro versos, Jorge de Sena não propõe um compromisso político a um Estado ou a qualquer outro tipo de organismo internacional; em questão, está o comprometimento de todo indivíduo com o lugar que ele habita, com o lugar com o qual ele estabelece relações mais profundas, sem obliterar o respeito que o indivíduo precisa manter para com os lugares que visita.

Negar o determinismo cultural e biológico é a maior força política que um indivíduo pode exercer, buscando encontrar tanto seu espaço quanto sua voz no mundo. Sua independência, porém, não é um isolamento, pois esta voz precisa encontrar os outros, abrir-se, e, no eterno processo dialógico, calar-se, para apurar os ouvidos e escutar - os outros, os sons do mundo. Na obra do poeta, a abertura está tanto para os mortos - das obras que nos ficaram - como para os futuros vivos, as gerações para as quais se entregará, direta ou indiretamente, a voz - ou as vozes - fixada no poema. $\mathrm{O}$ poeta não poderá exercer nenhum controle sobre estas escolhas. Em suas reflexões sobre a História e o trabalho de quem as deixará para a posteridade, Kant ressalta que

o louvável cuidado com os detalhes com que se escreve a história de seu tempo deve levar cada um naturalmente à seguinte inquietação: como nossos descendentes longínquos irão arcar com o fardo da história que nós lhes deixaremos depois de alguns séculos. Sem dúvida eles avaliarão a história dos tempos mais antigos, da qual os documentos poderiam estar perdidos há muito, somente do ponto de vista daquilo que lhes interessa (...) (2003, p. 22). 
Ao se pensar analogicamente esta passagem de Kant e o legado poético deixado por cada época, noto que esta "inquietação" não poderá ter como fim um desejo de controle, mas sim um comprometimento ético, reconhecedor dos próprios limites como poeta, dos limites humanos enquanto existência corpórea, capaz, no entanto, de existir na obra poética, de modo que a grafia supere, em termos temporais, a bio. Ficará aquilo que se entendeu do mundo, aberto a outros entendimentos futuros, pois "em poesia, ao contrário mais do que com outro tipo de comunicação se passa, nós só entendemos verdadeiramente aquilo que estamos dispostos a entender" (Sena, 1961, p. 9).

Esta escrita capaz de superar o tempo do corpo exigirá a consciência poética de que "o agora é um tempo do concreto, da corporalidade, por isso, não há mais a possibilidade de espaços limitadores, porque a beleza não está atada à circunscrição e à previsibilidade de nenhum jardim" (Figueiredo, 2003, p. 153). O imprevisível, inerente ao humano e contrário a regimes totalitaristas, não é possível em identidades medidas pelas informações biológicas. $\mathrm{O}$ que esperar de um mundo em que as responsabilidades atribuídas a um $\mathrm{Eu}$ não dizem respeito às escolhas e decisões tomadas por este $\mathrm{Eu}$ ? Além disso, o que posso aprender e apreender de alguém cujos traços particulares não são o gestual, a fala, o olhar, as ideias comunicadas, mas dados biológicos? Se a finalidade deste controle é, como ressalta Agamben, a segurança - e, por conseguinte, a manutenção da paz -, o erro é primário, ou, se se admite que não é realmente um erro, mas um falseamento discursivo em prol de um determinado grupo de poder, a aceitação destas medidas pode conduzir a humanidade a uma estratificação - sequer social, mas biológica, no caso - sem precedentes na nossa história. Há quase trinta anos, num texto de 1985, Gadamer (2007, pp. 25-26), já chamava a atenção para o fato de que

mais urgente do que nunca, (...), se tornou a tarefa de aprender a reconhecer no outro e na alteridade o comum. (...) Seria uma ilusão achar que só um sistema racional da utilidade, por assim dizer, uma espécie de religião da economia mundial, poderia regular a convivência humana sobre esse planeta que está se tornando cada vez mais estreito. A ciência do homem sabe que se exige cada vez mais do homem uma virtude política, assim como a ciência exigiu desde sempre uma virtude humana. (...) A ciência do homem, em toda a sua multiplicidade, tornou-se para nós todos uma tarefa ética e filosófica.

A associação entre economia (Gadamer) e segurança (Agamben) permite pensar num modelo atual e pouco propício ao ser humano, reduzido a uma utilidade ou simplesmente descartado de um sistema engendrado por fórmulas matemáticas, necessidade de acúmulo e desprezo aos sentimentos humanos. Este outro tipo de totalitarismo encontra semelhanças com os regimes ditatoriais que atravessaram $o$ século XX, ao propor um esvaziamento do indivíduo em nome de um tipo de entidade ao qual todos os seres humanos estão ligados. Obviamente, haverá nuances entre os diversos regimes, incluindo o atual, sobretudo no aspecto discursivo. Se o Portugal do Estado Novo (1933-1974), do qual Jorge de Sena se exilou, exigia um corporativismo estatal, o regime atual, fundado no desenvolvimento econômico como fim de si mesmo e no aparato de segurança, controlador central das práticas privadas e das identidades biológicas, requer uma espécie de ser humano absolutamente desconhecida do próprio ser humano. Não é sequer possível retornar, pelo menos do mesmo modo, ao cogito cartesiano, na separação do ser em corpo e espírito, cabendo ao corpo o lugar de objeto do "espírito pensante" (Detrez, 2002, p. 33, tradução do autor), um corpo-máquina "fabricado para Deus" (p. 33, tradução do autor). Se por um lado as Neurociências vêm indicando um caminho de observação que não cinge o homem em duas partes, 
entendendo o funcionamento da mente intrinsecamente associada ao corpo (Damásio, 2012), por outro lado o corpo vem sendo, pelo menos desde o surgimento das metrópoles, afastado de um determinado tipo de ambiente social que proporcione um contato humano mais direto. Com o advento da internet e todo o desdobramento do mundo virtual, o ser humano acabou sendo arrastado a este não-lugar,

mas o corpo físico, que não acompanha fisicamente esta operação, perde-se no universo atemporal das simulações. Com as possibilidades cada vez mais abrangentes de nãolugares, o corpo se definha em suas capacidades de percepção ambiental, catalisadas pelo desenvolvimento da cidade contemporânea, que produz cada vez mais, espaços anônimos e sem territorialidade explícita, onde o corpo não consegue se posicionar no papel de protagonista, de coadjuvante ou até mesmo de figurante na paisagem. (Takahashi, 2003, p. 150)

Embora Jorge de Sena não tenha vivenciado este mundo virtual, suas reflexões sobre o corpo e o modo como ele as formulou em seus poemas, bem como sua declarada e firme postura humanista, provocam a pensar no tanto que se perde e no risco ao qual se expõe o indivíduo ao ver-se coisificado e com poucas aberturas para escapar desta imposição. A resistência que ele pedia em "Chartres ou as pazes com a Europa" - "e a certeza de que este mundo tem de resistir/ - e há-de resistir - à grosseria,/ às bestas e ao vulgar, às multidões, a tudo:" (Sena, 2004, p. 98), ou a mensagem que deixava no longo poema "Carta a meus filhos sobre os fuzilamentos de Goya", escrito em Lisboa, menos de dois meses antes de partir para o exílio voluntário: "Acreditai que nenhum mundo, que nada nem ninguém/ vale mais que uma vida ou a alegria de tê-la." (Ibid, Ibidem, p. 65), permanece no ato poético, espaço em que a linguagem não se deixa dominar tão facilmente, situação diversa daquela da linguagem instrumentalizada da propaganda.

A poesia - ou à poesia - não se permite reduzir o homem a uma identidade biológica, medida por aparelhos que sabem ler impressões digitais, por exemplo, mas desconhecem a história de vida que aquelas digitais carregam. A poesia precisar ir a um outro. "A poesia é um novo andamento (...) da linguagem. É preciso ir além do que se pode dizer. Ultrapassar um mundo que não engana mais, não ilude" (Lins, 2005, p. 44).

Apesar de Ida Alves $(2009$, p. 65) afirmar que "a obra polifacetada de Jorge de Sena demonstra claramente o domínio da visão sobre os outros sentidos", não é demais lembrar a presença bastante forte destes outros sentidos. A audição, sentido incontornável para a poesia, ocupa um lugar extremamente relevante em Arte de Música, de 1968. Música que se faz com inúmeros instrumentos, estes objetos que serão, para o músico, uma extensão do próprio corpo. Música que se faz, portanto, com o corpo sentindo e, não menos, pensando, pois se expressar musicalmente exige que emoção e razão não se separem nem que haja uma hierarquização de uma sobre a outra.

Com o poema "A Piaf", encerro, em coro, este trabalho:

Quem tinha assim a morte na sua voz

e na vida. Quem como ela perdeu

toda a alegria e toda a esperança

é que pode cantar com esta ciência

do desespero de ser-se um ser humano

entre os humanos que o são tão pouco. (Sena, 2004, p. 81) 